\title{
"SuperWomen": A Smart Mobile Application for Social Security focusing Threats and Supports for Women
}

\author{
https://doi.org/10.3991/ijim.v15i03.17555
}

\author{
Natasha Tanzila Monalisa ${ }^{(凶)}$, Shinthi Tasnim Himi, Nayeema Ferdous, \\ Md. Ezharul Islam, Anup Majumder \\ Jahangirnagar University, Dhaka, Bangladesh \\ natasha.tanzila786@gmail.com
}

\begin{abstract}
Today in our modern society men and women are said to be given equal rights, having no gender discrimination but women are still considered weak and endlessly facing rape, domestic violence, eve-teasing, workplace violence, physical assault, cyberbullying even being killed. In South Asian countries there are thousands of cases regarding violence against women, having a comparatively low rate in Western and European countries though not that negligible to ignore. The use of ICT including smartphone applications can be an aid in building awareness and support against these issues. Although several applications were developed worldwide, but not out there online for sensible use. In this paper, we aspire to present a system that works on women security developed especially for women but is useful to anyone irrespective of any gender. Finally, the system has been developed into a mobile application. Survey feedback of this application shows that it takes care of each pre-incidental and post-incidental condition like an expert. This application provides user-friendly navigation for women with less technical knowledge. Its key features are secret button emergency SMS alert, location sharing with any social media, lawyer and psychological chatbot, pictorial self-defense techniques, etc. Its voice-controlled siren feature is also a great help for physically challenged individuals, that works even on the lock screen. The effectiveness of this application has been justified through extensive literature review, application benchmark, performance evaluation, user survey, deployment in Google Play Store. We believe that this will bring a holistic resolution to safeguard suppressed women worldwide.
\end{abstract}

Keywords - Women Security, Smartphone Application, Android, Chatbot, Threat Alert, Social Security, GPS Tracking

\section{Introduction}

Helen Maxine Reddy, an Australian-American singer, actress, and activist once sang, "I am woman, hear me roar, in numbers too big to ignore, and I know too much to go back and pretend." This quote says a lot about the present condition of women in society. Female harassment and sexual violence have emerged as the most pervasive security threats for women around the world. According to a case study of the Sustainable Development Goals Fund, "nearly two out of three women have experienced 
gender-based violence during their lifetime, and domestic violence is a common, though largely underreported, occurrence [1]." Even in Europe, the situation is dreadful. According to data published by Ipsos [2], a statistic has been presented on the share of people in selected European countries who think sexual violence is one of the top three issues women are facing as of 2019, where the highest percentage was 44, from Spain. The picture of USA is no exception, in a report published recently in CDC, it has been stated that "Nearly 1 in 5 women have experienced completed or attempted rape during her lifetime [3]." Though in the modern era, where men and women are said to be given the same rights, where women are stepping outside the confines of the house in quest of education and employment are still living in the fear of being sexually abused and harassed. Rape cases are ever-increasing in Asian countries too. A statistic from 2001-2019 shows that there are, in total, 14718 rape victims in Bangladesh [4]. Even the act of killing the victim brutally after abuse is increasing rapidly. In a dreadful case in 2019, Nusrat Jahan Rafi was doused in kerosene and set on fire on April 6, on the very roof of her school building. Just because some days earlier, she had filed a sexual abuse complaint with the police against the madrasa principal. However, she had been repeatedly warned to withdraw the case after that [5]. According to an article by Dhaka Tribune: "BMP, a women-led organization working to protect women rights, revealed that these violent incidents occurred till June 30, 2019. Out of the total 731 incidents of sexual violence, 592 were raped, 113 were gang-raped, 26 were killed after being raped, and 123 were victims of attempted rape, said Bangladesh Mahila Parishad [6]." The punishment for such a heinous act is rather not exemplary at all. Other than that domestic violence, eve-teasing, workplace violence, physical assault, cyberbullying, stalking all these types of violence are seriously questioning women security issues in our society.

The alarming condition provoked lots of individuals to develop mobile applications and devices related to women safety and security as mobile applications are increasingly becoming ubiquitous, penetrating and transforming everyday social views and practices [7]. India, being the 5th ranked country all over the world in the count of the highest rape cases [8] a lot of applications have been developed aiming to mitigate the mishap. 'SafetiPin' [9], is one of the most popular applications to the criteria which can share location and provide safe routes. Pakistani application, 'MehfoozAurat' [10] and ‘\#MeToo' [11], European application 'Ana Bella' [12], American application 'The Sojourner Peace app' [13], Bangladeshi women safety application 'HearMe' [14] are working relentlessly to safeguard women in homes and outside places. Other than 'HearMe' [14], none of the above-mentioned applications provide features like lock screen access or emergency siren. However, applications like these are mostly available for specific regions and some of them are available worldwide too, but those are targeted at women of their respective countries, so cannot bring any help to other countries women. As an example, 'HearMe' [14] is designed to ensure protection to the women of Bangladesh but it cannot be found in Google play store or any online media, also not very helpful if considered for other regions. Moreover, there's no such application that focuses on the visually impaired or people with other physical challenges.

Thus, taking every factor of threats into consideration, in this paper we propose and develop a mobile application 'SuperWomen' to safeguard women and in general to 
support every individual that is considered weak in the society. This application guarantees a complete package for women safety. Firstly, 'Voice Command Siren for impaired persons' is a feature that enables emergency siren with a scream even though the screen is locked. A non-technical person or impaired person can make the best use of it. Secondly, 'Interactive Lawyer bot' is one of the exclusive features of our application that lets people learn about the latest laws and help the women to get their proper honor. Thirdly, 'Psychiatric help in English and Bangla language' is a unique feature of this application. Women in rural areas are not habituated yet to go to an actual doctor to share their mental health. This bot has a feature that can help rural women as well as girls at teenage to fight with nightmares that they are facing alone, in their native language. Fourthly, the 'RAD (Rape Aggression Defense) Technique' is a pictorial representation of RAD self-defense techniques. If any girl wants to defend herself in any sudden attacks, she can do it without using any weapon by following the techniques. Lastly, the 'Online ambulance and Medicine' section helps booking ambulances through this application with one click and medicine can be at doorsteps including sanitary napkins and other medical products without hesitations or shame. The use of "SuperWomen" is not limited to any particular sector of people. Older or lower educated parents who may find it uncomfortable on smart mobile learning in informal learning environments can also be benefited by "SuperWomen" for its trouble-free simpler navigation system [15]. Even for children, this application can be an early learning material for learning self-defense and handle any emergency. "SuperWomen" can also contribute to reduce sexual violence to children that cause them long term physical and mental health problems [16]. All these features make "SuperWomen" an efficient security tool for women, the elderly, the handicapped, and children.

The rest of the paper is organized as follows: Section 2 outlines some 'Related Works', section 3 presents 'System Development Procedure and Method', section 4 depicts 'Proposed Application Model and System Design', followed by section 5 and 6 which demonstrates 'System Implementation' and 'System Evaluation' respectively. Finally, section 7 concludes the paper with a few future works.

\section{Related Works}

By undergoing several works, we came across many android applications that have been developed and evaluated to shield women against all types of assault and rampage. Our evaluation has manifested some advantages and disadvantages that have allowed shaping our application to the level of perfection by incorporating more features.

In [9], Viswanath et al. presented a paper on a community based social application 'SafetiPin'. Its 'community-communication' enables engagement with neighbors, 'safety scores' option is available for ensuring road safety. The concern is, not all routes are known by the map which can put someone in a dilemma.

In [10], Sarosh et al. presented a Pakistani application 'MehfoozAurat'. It has a safe route, emergency alert, audio recording, and self-defense tips features. But it has no use in other countries, as no safety route scores could be obtained. 
In [12], Kaylan Santos developed a mobile application 'Ana Bella' that focuses on creating a network of surviving women to have friends, empower themselves, and be happy. The application includes some chatting options for sharing the experience of a victim. It could be a helpful application for PTSD and a violent victim but emergencies and dangers cannot be mitigated by it. Also, this application is not available in the play store, can be found on a less popular platform but as soon as it's installed and opened it crashes showing a black screen.

In [13], the 'Sojourner Family Peace Center' developed an application to help individuals impacted by domestic abuse connect with emergency help. This application provides a list of victim-advocate and legal services. Although this American application seems a promising one but the drawback is, it's not available for use to individuals other than the Sojourner community.

In [14], Akash et al. presented a paper on one of the Bangladeshi applications 'HearMe' for women that has Lock screen access, Instant siren, SMS alert, Fake call, also some laws are mentioned in this application. But as there is no voice control option it's hard for people with disabilities to utilize this application. And it's not available in internet resources.

In [17], Ahmed et al. presented a paper on a web page and small application named 'Protibadi' containing harassment stories that have a 'save me' button that turns on a loud sound. Not having a cooperative user interface and a poor number of features makes it not worthy enough to rely on.

In [18], 'Photonapps' developed a mobile application 'Shake2Safety' for women safety that has a unique 'No keypress' feature with shake sensitivity. Yet the most important feature in women safety applications 'location sharing via any social media' is not possible.

In [19], 'MobileSoftware AS' developed an application-based women security system titled 'bSafe'. This application can send location, can make fake call appearance, has an automatic alarm function. But as every feature needs internet support, it could be troublesome for many of the users.

In [20], 'Awesome Apps Inc' developed an application titled 'Women Safety'. This application can send locations to the email addresses of the listed contacts, can capture images and record videos. But its efficiency to handle an emergency is questionable, as it is fully dependent on internet connection.

In [21], 'Portal Perfect' developed a women safety application titled 'Raksha'. This application lets its users send emergency email and text, get the location of the nearby police station by pressing a button, and has features like organ donation. But these handful features are not sufficient for the complete protection of a woman.

Table 1 shows a comparison of some popular applications with "SuperWomen". It reveals that "SuperWomen" surely has unique features. Though most of the applications contain secret key location sharing and some of them have lock screen access, but none has the features like: Law and psychological helping bot, Emergency medical and helpline services. These particular features make "SuperWomen" more resourceful and efficient in every situation. 
Table 1. Feature Comparison with Related Applications focusing Women Security

\begin{tabular}{|l|c|c|c|c|c|c|c|}
\hline $\begin{array}{c}\text { Application } \\
\text { Name }\end{array}$ & $\begin{array}{c}\text { Accessing } \\
\text { Lock } \\
\text { Screen }\end{array}$ & $\begin{array}{c}\text { Law } \\
\text { And } \\
\text { Psycho } \\
\text { Bot }\end{array}$ & $\begin{array}{c}\text { RAD } \\
\text { Defense } \\
\text { Techniques }\end{array}$ & $\begin{array}{c}\text { Emergency } \\
\text { Medical } \\
\text { Services }\end{array}$ & $\begin{array}{c}\text { Secret } \\
\text { Key } \\
\text { Location } \\
\text { Sharing }\end{array}$ & $\begin{array}{c}\text { Emergency } \\
\text { Helpline } \\
\text { Services }\end{array}$ & $\begin{array}{c}\text { Enabling } \\
\text { Panic } \\
\text { Siren }\end{array}$ \\
\hline Safetipin & No & No & No & No & Yes & No & No \\
\hline MehfoozAurat & No & No & No & No & Yes & No & No \\
\hline Protibadi & No & No & No & No & No & No & No \\
\hline Shake2Safety & Yes & No & No & No & Yes & No & Yes \\
\hline bSafe & No & No & No & No & Yes & No & Yes \\
\hline HearMe & Yes & No & No & No & Yes & No & Yes \\
\hline Raksha & No & No & No & No & Yes & No & No \\
\hline WomenSafety & No & No & No & No & Yes & No & Yes \\
\hline Ana Bella & No & No & No & No & No & No & No \\
\hline $\begin{array}{l}\text { SuperWomen } \\
\text { (proposed) }\end{array}$ & Yes & Yes & Yes & Yes & Yes & Yes & Yes \\
\hline
\end{tabular}

\section{System Development Procedure and Method}

The overall system architecture [22] of our proposed system has been represented in Figure 1. Any user with a smartphone having internet access can share their location via any social media. It requires searching for a location in "Google maps", fetching data from the "Google's Bigtable" database. After the retrieval of location, it can also be sent as an emergency SMS using GSM module when a button is pressed. By using the mobile network, a call can be placed to the helplines and organizations. Using the microphone, voice recording, and recognition, a siren is triggered through the loudspeaker of the phone.

The Whole system has been implemented using android studio. Several Java and XML files including different modules of the android studio have been used for providing various functionalities. Pocketsphinx has been used for speech recognition and Chatfuel for chatbot development. Necessary permissions have been taken in the android manifest section. After successfully finishing the coding part, it had been run on emulator pixel 2 API 29 that showed perfect layout and the features ran smoothly as well.

\section{Proposed Application Model and System Design}

In this section we present and describe application model and system design of our application. 


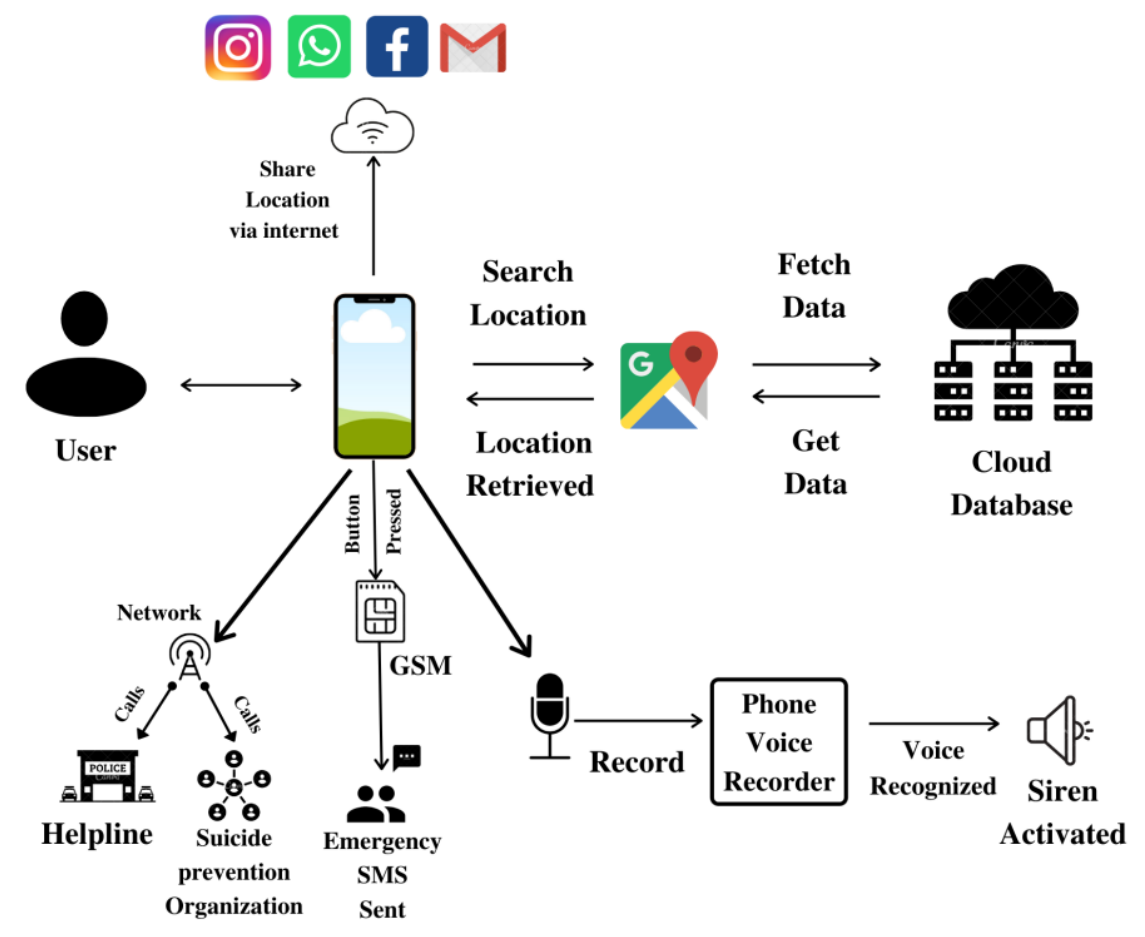

Fig. 1. System Architecture of Proposed System

\subsection{Application model}

The application model of the proposed system can be best described by explaining its components. Figure 2, demonstrates a flowchart representation of the system model and the components of the system are described below:

1. Interactive bot enriched with laws: We cannot think of a lawyer who will always be at our service. In some cases, it is seen that women are afraid to file a report to the police against the offender as she thinks maybe he will get minimal punishment and then harass her family and her. If she had known the proper laws that he will be in jail for a long time, even not permitted to leave the country during that time, then she could have taken proper and lawful steps. As a result, the suicidal rate would have reduced to a great extent among abused women. Our bot can be her companion to know the laws without the need of a lawyer, and she can even know further if information is not available in the bot by our "talk to human" feature.

2. Lock screen access via voice control to start siren of police van: It is not always the case that a user will be able to open the application, play the siren or send location. There are times when she will not be able to even touch the phone or press any button to seek emergency help. In our application, by simply saying the keyword "help me" 
a thundering siren mimicking the siren of a police van is played in the sender and receiver side.

3. Holding secret key for text sending via messaging: In some public transport if someone is touching a woman intentionally or any such situation occurs, and she can be in contact with her phone and can press her phone's lower volume button, a text message saying "Help Me Please. My Current Location:" with the accurate location of the sender is sent to all the contacts saved in her trusted contact section of the application.

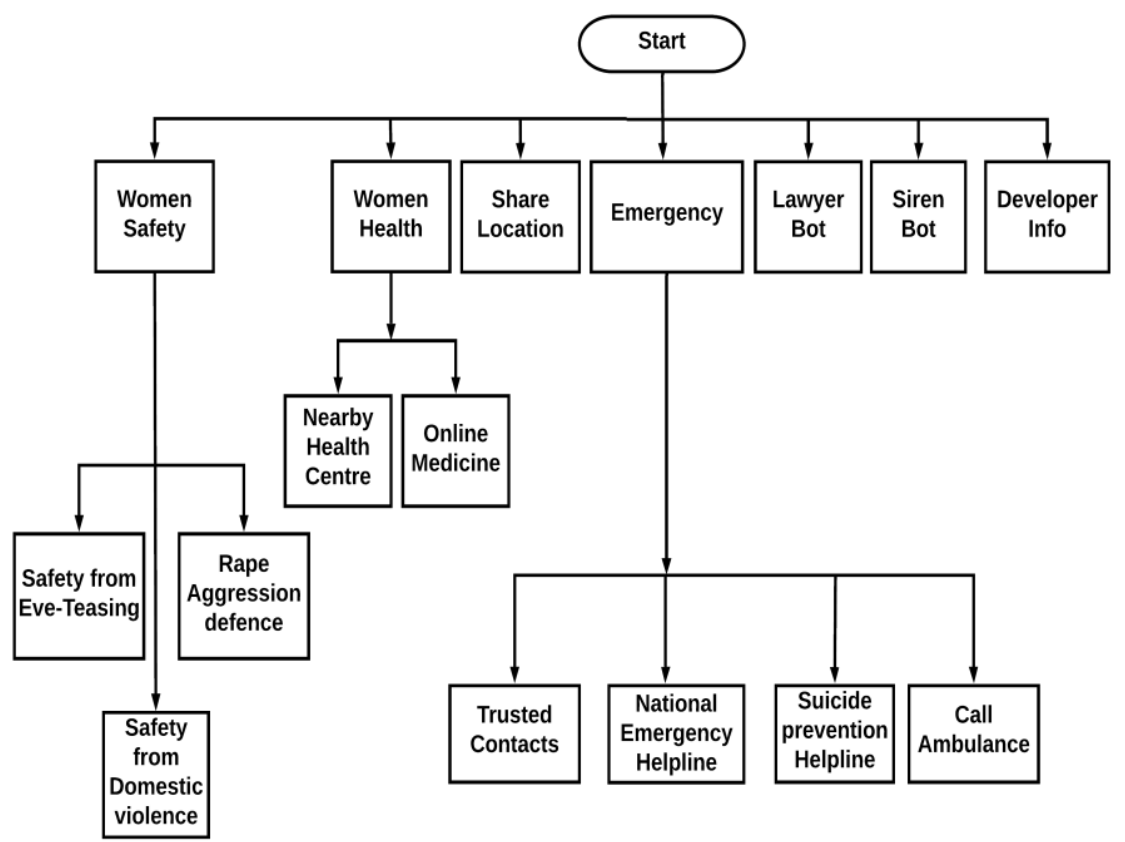

Fig. 2. Proposed Application Navigation Flowchart

4. Sharing accurate location via any social media: If a woman wants to share her location with a trusted person, can do it from the application with any social media, as we believe no boundaries should be there at the time of self-protection. Any shareable media like Bluetooth, messenger applications like Whatsapp, Facebook messenger even email sites and all the available media can be found as options.

5. Psychiatrist bot in English and Bangla: Women in South Asian countries are still not comfortable to talk with their doctors freely, they tend to hide many things about their mental health so the doctor couldn't help them properly. We tend to give urban as well as rural women a chance to share their feelings and get mental help in complete privacy. It is designed in Bangla too, so the knowledge of English is not mandatory.

6. Find nearby hospital: As people can't think properly at the time of danger, it is very hard for them to call for help or search for hospitals especially for women when she 
is already broken down mentally. So, this application provides one-click service to find a nearby hospital.

7. Online Medicine Store: As we know there's still a taboo in our society about sanitary napkins and personal products, women do not find it convenient to buy them in person. So, this application lets her buy it online without any hesitation.

8. One-click Police Call: There's a police helpline in almost all the countries of the world including Bangladesh that serves 24/7. So, the women who are in danger or any crisis point, they can call the cops with just one click in this application so that the police can rescue her as soon as possible. It would be very easy for the victim to click than searching the police numbers.

9. One-click nearby ambulance booking with customization: This application lets anyone with an internet connection to search for nearby ambulance in map and book it with customization like ac or non-ac, with oxygen cylinder or not, and other such tremendous varieties.

10. One-click call to suicide prevention number: If someone has locked themselves in a room or trying to suicide but in no way we can help them. With this application, we can click on the suicide prevention number that enables us to contact an organization that can help us out in such cases.

11. Rad training: Army techniques are known as the best self-defense techniques all over the world. Without any weapons, it can make the offender weak even if he is stronger in strength. We provided some tricks of such with pictorial description to guide the women in need.

\subsection{System design}

In this section, we present the design of our proposed system through use case diagrams [23] for a better understanding of the system. Use cases for three of the primary features have been presented in Figure 3. Lawyer Bot diagram shows how users and the system interact through a messenger bot, Emergency SMS demonstrates the retrieval of location and sharing to media. Lastly, Voice-Controlled Siren illustrates the activation of police siren by recording.

\section{System Implementation}

In this section we present the implementation details of proposed system through depicting system environment and system archetype of the "SuperWomen".

\subsection{System environment}

Table 2 and Table 3 shows the necessary hardware and software used by the developer and requirements of the user for better experiencing the "SuperWomen" application without any delays or troubleshooting. 


\subsection{System archetype}

Like any sound mobile application, "SuperWomen" has some quality aspects, which also reflect its superior system archetypes [24]:

- User-friendly UI

- Easier navigation

- Memory efficiency

- User security

- Trustworthy information.

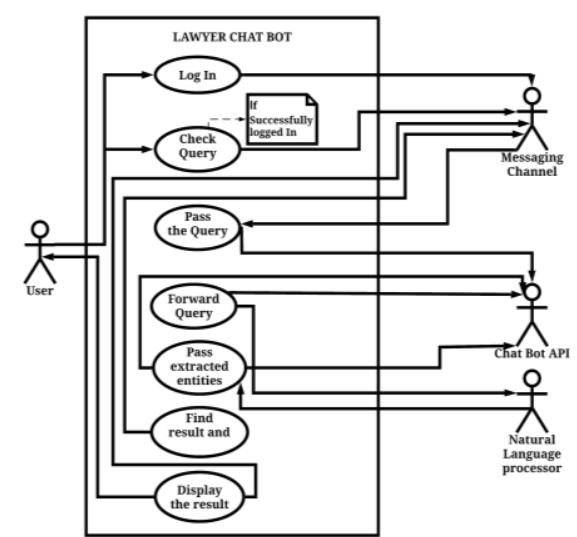

(a)

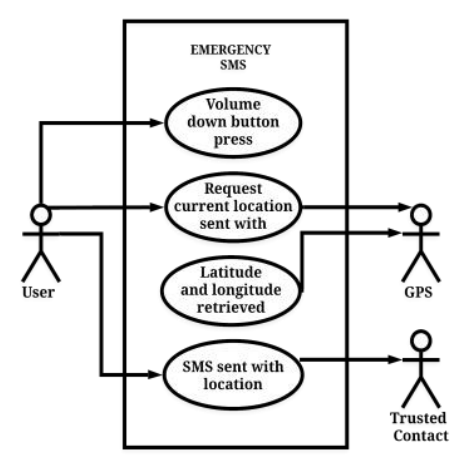

(b)

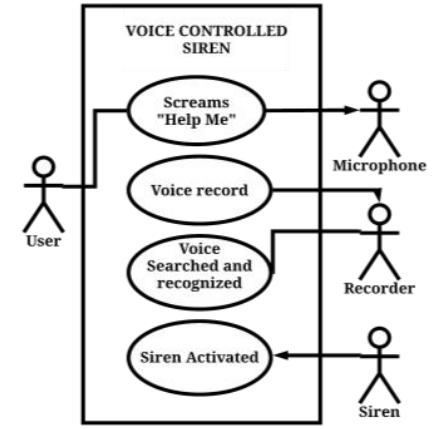

(c)

Fig. 3. Use cases of Proposed System: (a) Lawyer Bot, (b) Emergency SMS, (c) Voice-Controlled Siren 
Table 2. System Development Environment

\begin{tabular}{|l|l|}
\hline \multicolumn{1}{|c|}{ Platform Used } & Windows 10 \\
\hline Processor Used & Core i5 \\
\hline Android Studio Version Used & 3.6 .1 \\
\hline Minimum RAM Required & $8 \mathrm{~GB}$ \\
\hline API level Used & 29 \\
\hline AVD Used & Pixel 2 \\
\hline Hardware Used for Location & GPS \\
\hline Other Software Used & PocketSphinx, Chatfuel \\
\hline
\end{tabular}

Table 3. Hardware and Software Requirements of User

\begin{tabular}{|l|l|}
\hline Minimum Android Version & 4.4 \\
\hline Minimum RAM needed & $1 \mathrm{~GB}-2 \mathrm{~GB}$ \\
\hline Compatible Network Needed & 2G-4G \\
\hline Permissions & Location, Contact, SMS, Microphone \\
\hline
\end{tabular}

As in Figure 4, firstly by clicking "Let's Start" button, the main menu appears. From 7 menu items:
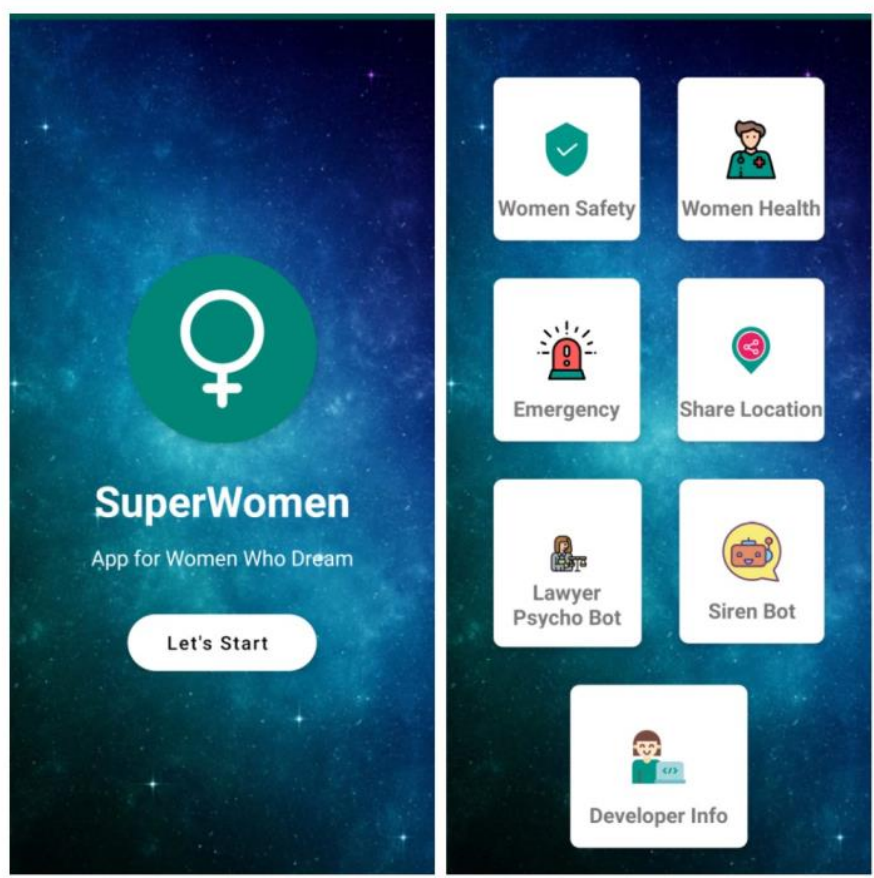

Fig. 4. Interface to the features of "SuperWomen" application 
1. Women security has some pdfs for self-defense with interactive pictures.

2. Women safety uses the location and shows the list of nearby health centers by one click and medicines could be at doorsteps by a few selections.

3. In the emergency section, by providing "contact permission" and saving phone numbers in trusted contacts, and giving "SMS permission" the user can send emergency texts "help me please: location" by pressing the volume down button for 2 seconds. Some necessary helpline numbers are also included and "Call an ambulance" shows nearby ambulance by GPS.

4. "Share location" uses "location permission and SMS permission" and then can send location via Bluetooth, Email, Instagram, Messenger, Snapchat, Facebook, or any social media.

5. "Lawyer \& Psychiatric Bot" takes to a messenger chat and by clicking simple numbers or letters anyone can know about prevalent laws for women or get relevant psychological help.

6. Our exclusive menu "Siren Bot" can be enabled by giving "Microphone Permission", if anyone even when the screen is locked screams "Help me", a loud police siren ring.

7. The "Developer Info" item contains information about the developers of this application.

\section{System Evaluation}

This section presents the application benchmark against some benchmark criteria and performance evaluation of the system from user feedback.

\subsection{Application benchmark}

In this era of technological surge, one can find tons of mobile applications to satisfy one's needs. As the number of mobile applications is increasing so is the competition between them to survive. A mobile application thus needs some benchmark to fulfill, for satisfying the end-users. "SuperWomen" have been evaluated against some efficient Device performance and troubleshooting mobile application performance strategies etc.

Table 4 shows the evaluation result against the benchmark criteria which reveals that "SuperWomen" application satisfies each of them without any glitch. 
Table 4. Application Benchmark

\begin{tabular}{|l|l|}
\hline \multicolumn{1}{|c|}{ Benchmark Criteria } & \\
\hline App StartUp & 1 second \\
\hline Battery Time while Using an App & 1 second \\
\hline Memory Consumption & $0.2 \%$ per hour \\
\hline Internal Storage Used & $55.15 \mathrm{MB}$ \\
\hline Hardware / Software Variations & Supports 97\% Android Devices \\
\hline Usage with Other Apps & Runs perfectly \\
\hline Lag or Sluggish response & Not encountered \\
\hline App Restarting, Locking Up, Freezing & Not encountered \\
\hline
\end{tabular}

\subsection{User feedback analysis}

An online survey for analyzing the feedback of "SuperWomen" application was conducted. The feedback was taken from 130 individuals. Of them, 28.3\% are aged between 18 and 25, 28.3\% are aged between 25 and 50, and others are below 18, and we observed some severe facts. The observations and analysis are assembled in Figure 5. Figure 5(a) shows that a woman is most unsafe at her own house and according to our survey it is $24.5 \%$, more than even the crowded places or public transports which came out to be $14.3 \%$ and $19.5 \%$ respectively. And surprisingly $28 \%$ of women faced violence by their relatives, although strangers are still in the first position among the assailants.

We made them use the "SuperWomen" application and 83.2\% said they liked it a lot. Their ratings on our features have been shown in Figure 5(b), named performance evaluation, $42 \%$ selected the Emergency section of the application to be the most useful, which has an emergency text sending feature to trusted contacts along with the national emergency helpline number, suicide prevention number, and call nearby ambulance number. Then $26 \%$ felt that voice-controlled siren could help them in unavoidable circumstances. Even women health caught the eyes of the users, on the contrary, share location and lawyer bot options weren't found as salient as others. These two options along with women safety will eventually help the women in the long run. 


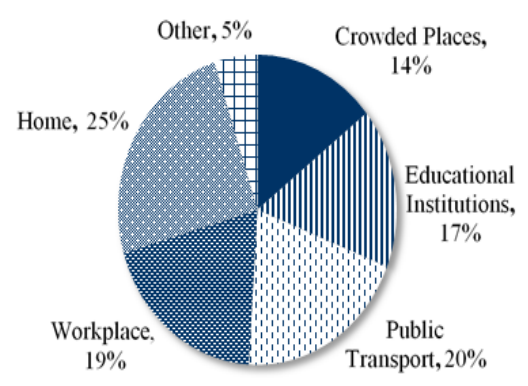

(a)

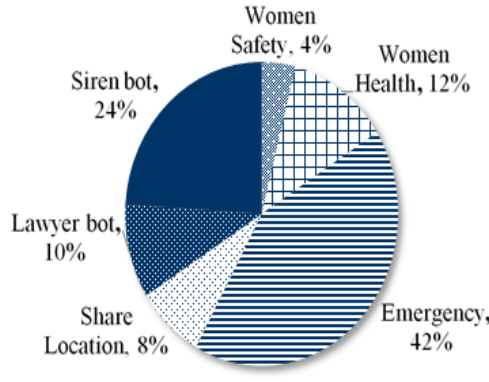

(b)

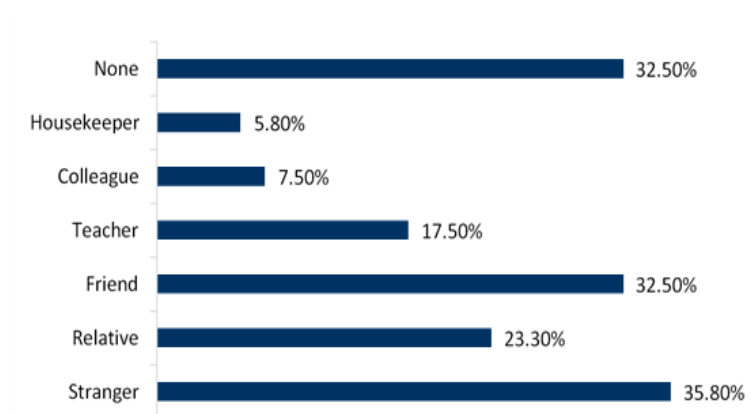

(c)

Fig. 5. User feedback Analysis: (a) Spots of the Incidents, (b) Performance Evaluation, (c) Category Metric of Assailants.

\subsection{Application deployment and feedback}

After developing "SuperWomen", we deployed the application successfully in Google play store [25]. This application has successfully passed the standard screening process to ensure the security and privacy of the users through Google Play Protect [26]. Unlike most of the applications downloaded from the play store, "SuperWomen" does not contain any advertisement which reduces user concerns regarding adware that can threaten their privacy and mobile system security [27].

Within two weeks of initial deployment "SuperWomen" has been downloaded to $100+$ devices and received 100 five-star reviews. This application got many constructive opinions from users around the world. Almost all the comments got positive responses. 


\section{Conclusion and Future Works}

In this paper, we intended to present an efficient way of securing women from any sort of assault and violence by providing them an ultimate technological solution, a mobile application "SuperWomen". Though this application has some special focus for women but it is developed to cover a broader sense i.e. anyone facing an emergency can make use of it. We got feedback that this application is a complete package which scored 5 out of 5 from $95.4 \%$ of the users that is more than our expectation. It not only efficiently tackles any emergency but also prepares the users for surviving any odd situation. Moreover, it provides counseling for any psychological issue and makes aware of the latest laws. Though several papers were found on women security mobile applications and many of them showed promising features, most of them were not found on app stores or were not for our region. "SuperWomen" can be downloaded easily from stores. This application provides a user-friendly UI for easier navigation. It has some exclusive features like a voice-controlled siren over the lock screen, emergency SMS with location sharing, lawyer and psychological bot that are bound to be of great use to the rural, urban as well as people with disabilities.

From this time forth, we will further progress by implementing a spy camera feature embedded with AI for detecting violence and sending immediate alert automatically. We also plan about women empowerment by providing them with a platform through this application that helps them to boost up their careers. By incorporating all these features this application can build a safer, reliable, and independent women community opening for the future researchers a door for larger contributions.

\section{$8 \quad$ References}

[1] Sustainable Development Goals Fund, 2020. "Addressing Violence Against Women In Bangladesh". [Online]. Available at: https://www.sdgfund.org/case-study/addressing-violence-against-women-bangladesh . [Accessed: 23 April, 2020]. https://doi.org/10.1177/ 1077801220963906

[2] Statista, 2020. "Sexual Violence in Europe 2019 | Statista". [online] Available at: https:// www.statista.com/statistics/1072929/sexual-violence-in-europe/ [Accessed 8 September, 2020].

[3] Centers for Disease Control and Prevention, 2020. "Sexual Assault Awareness". [online] Available at: https://www.cdc.gov/injury/features/sexual-violence/index.html [Accessed 8 September, 2020].

[4] Odhikar.org, 2020. "Statistics on Violence against women". [Online] Available at: http:// odhikar.org/statistics/statistics-on-violence-against-women/. [Accessed: 27 June, 2020].

[5] Dhaka Tribune, 2020. "Has Sexual Violence Become Part of Our Culture?". [online] Available at: https://www.dhakatribune.com/opinion/op-ed/2019/07/22/has-sexual-violence-become-part-of-our-culture [Accessed: 23 April, 2020].

[6] Dhaka Tribune, 2019. "A shocking 731 rapes reported in first six months of 2019”, [Online]. Available at: https://www.dhakatribune.com/bangladesh/nation/2019/07/08/a-shocking-731 -rapes-reported-in-first-six-months-of-2019. [Accessed: 25 June, 2020].

[7] A. Stathopoulou, Z. Karabatzaki, D. Tsiros, S. Katsantoni and A. Drigas, "Mobile Apps the Educational Solution for Autistic Students in Secondary Education", International Journal 
of Interactive Mobile Technologies (iJIM), vol. 13, no. 02, pp. 89, 2019. Available: https://doi.org/10.3991/ijim.v13i02.9896

[8] E. Khan, 2020. "Top 10 Countries With Highest Rape Crime In The World - Wonders list". [online] Available at: https://www.wonderslist.com/10-countries-highest-rape-crime [Accessed: 23 April, 2020].

[9] K. Viswanath, and A.Basu, "SafetiPin: an innovative mobile app to collect data on women's safety in Indian cities". Gender \& Development, vol. 23, no. 1, pp. 45-60, 2015. Available: https://doi.org/10.1080/13552074.2015.1013669

[10] M. Sarosh, M. Yousaf, M. Javed, and S. Shahid, "Mehfoozaurat: Transforming smart phones into women safety devices against harassment". Proceedings of the Eighth International Conference on Information and Communication Technologies and Development - ICTD '16, 2016. Available: https://doi.org/10.1145/2909609.2909645

[11] J. Sheikh and Z. Fayyaz, "\#MeToo: An App to Enhancing Women Safety", Advances in Usability, User Experience and Assistive Technology, pp. 546-553, 2018. Available: https://doi.org/10.100/978-3-319-94947-5 55. https://doi.org/10.1007/978-3-319-94947$\underline{5 \_55}$

[12] A. Bella, 2020. “Ana Bella For Android - APK Download”. [online] APKPure.com. Available at: https://apkpure.com/ana-bella/com.itinerarium.womenempowerment [Accessed: 8 September, 2020]. https://doi.org/10.1093/oao/9781884446054.013.2000000015

[13] BizTimes - Milwaukee Business News, 2020. "New Sojourner Peace App Launches For Survivors of Domestic Violence". [online] Available at: https://biztimes.com/new-sojourner-peace-app-launches-for-survivors-of-domestic-violence/[Accessed: 8 September, 2020].

[14] S. Akash, M. Al-Zihad, T. Adhikary, M. Razzaque and A. Sharmin, "HearMe: A smart mobile application for mitigating women harassment", 2016 IEEE International WIE Conference on Electrical and Computer Engineering (WIECON-ECE), 2016. Available: https://doi. org/10.1109/wiecon-ece.2016.8009093

[15] S. Papadakis, N. Zaranis and M. Kalogiannakis, "Parental involvement and attitudes towards young Greek children's mobile usage", International Journal of Child-Computer Interaction, vol. 22, pp. 100-144, 2019. Available: https://doi.org/10.1016/j.ijcci.2019.100144

[16] E. Sediyono, W. Kristinawati and M. Paseleng, "Empowering Teachers in the Socialization of the Anti-Sexual Violence Behavior in Primary Schools", International Journal of Interactive Mobile Technologies (iJIM), vol. 12, no. 8, pp. 20, 2018. Available: https://doi. org/10.3991/ijim.v12i8.9641

[17] S. Ahmed, S. Jackson, N. Ahmed, H. Ferdous, M. Rifat, A. Rizvi, S. Ahmed, and R. Mansur, 2014. "Protibadi: A platform for fighting sexual harassment in urban Bangladesh". Proceedings of the 32nd annual ACM conference on Human factors in computing systems - CHI '14, pp. 2695-2704, 2014. Available: https://doi.org/10.1145/2556288.2557376

[18] Photonapps, 2020. "photonapps", [Online]. Available at: https://photonapps.wordpress. com/ [Accessed: 23 April, 2020].

[19] Mobile Software AS, 2020. "BSafe - Never walk alone", [Online]. Available at: https://getbsafe.com/. [Accessed: 23 April, 2020].

[20] Awesome Apps Inc., 2019. “Women Safety - Apps on Google Play,” [Online]. Available at: https://play.google.com/store/apps/details?id=com.awesome_apps.women_safety\&hl= en [Accessed: 05 May, 2020]. https://doi.org/10.7717/peerj.4849/table-6

[21] Portal Perfect, 2018. "Raksha, A Women's Safety App". [Online] Available at: https://play. google.com/store/apps/details?id=com.portalperfect.sosapp\&hl=en. [Accessed: 05 May, 2020]. 
[22] T. Weilkiens, J. Lamm, S. Roth and M. Walker, Model-based system architecture. John Wiley \& Sons, 2015. https://doi.org/10.1002/9781119051930

[23] O. Nikiforova, J. Sejans and A. Cernickins, "Role of UML Class Diagram in Object-Oriented Software Development". Applied Computer Systems, vol. 44, no. 1, pp. 65-74, 2011. Available: https://doi.org/10.2478/v10143-011-0023-4

[24] William Braun, "The System Archetypes", System, 2002. Available: http://my2.ewb.ca/ site_media/static/attachments/group_topics_grouptopic/86984/systemarchetypes.pdf.pdf [Accessed: 1 December, 2020].

[25] ThirdBit, 2020. "SuperWomen". [Online] Available at: https://play.google.com/store/ apps/ details?id=com.wsec\&hl=en [Accessed: 06 July, 2020].

[26] Google Inc., 2017. "Android - Google Play Protect." (2017). [Online] Available at: https://www.android.com/play-protect/ [Accessed: 01 December, 2020].

[27] M. Alani, "Android Users Privacy Awareness Survey", International Journal of Interactive Mobile Technologies (iJIM), vol. 11, no. 3, pp. 130, 2017. Available: https://doi.org/ $\underline{10.3991 / i j i m . v 11 i 3.6605}$

\section{Authors}

Natasha Tanzila Monalisa is at the Department of Computer Science and Engineering, Jahangirnagar University, Savar, Dhaka, Bangladesh. During her BSc. she participated in many educational seminars and conferences. Her research interest includes deep learning, artificial intelligence, natural language processing and cyber security.

Shinthi Tasnim Himi is at the Department of Computer Science and Engineering, Jahangirnagar University, Savar, Dhaka, Bangladesh. Her research interest includes big data analysis, machine learning, artificial intelligence, and human-computer interaction. Email: shinthitasnim89@gmail.com

Nayeema Ferdous is at the Department of Computer Science and Engineering, Jahangirnagar University, Savar, Dhaka, Bangladesh. Her research interest includes IoT, mobile application development, neural networking and augmented reality. Email: nayeemaferdous987@gmail.com

Md. Ezharul Islam is an Associate Professor in the Department of Computer Science and Engineering, Jahangirnagar University, Savar, Dhaka, Bangladesh. He received his $\mathrm{PhD}$ degree in Information and Communication Systems from Okayama University, Japan. His current research interests are internet of things, machine learning, wireless sensor networks, and optimization algorithms. Email: ezharul.islam@juniv.edu

Anup Majumder received his B.Sc. (Honors) and M.Sc. in Computer Science and Engineering from Jahangirnagar University, Dhaka, Bangladesh in 2014 and 2015 respectively. Currently, he is working as a lecturer in the Department of Computer Science and Engineering, Jahangirnagar University, Dhaka, Bangladesh. His research interest is focused on Deep Learning specially to the Machine Learning and Expert System and Data Mining. Email: anupmajumder@juniv.edu

Article submitted 2020-08-05. Resubmitted 2020-12-01. Final acceptance 2020-12-01. Final version published as submitted by the authors. 